\title{
Time-varying Hedge Ratios: A Principal-agent Approach
}

\author{
John K. M. Kuwornu, W. Erno Kuiper, \\ Joost M. E. Pennings and Matthew T. G. Meulenberg ${ }^{1}$
}

(Original submitted January 2003, final revision received August 2005, accepted September 2005.)

\begin{abstract}
We use the classic agency model to derive a time-varying optimal hedge ratio for low-frequency time-series data: the type of data used by crop farmers when deciding about production and about their hedging strategy. Rooted in the classic agency framework, the proposed hedge ratio reflects the context of both the crop farmer's decision and the crop farmer's contractual relationships in the marketing channel. An empirical illustration of the Dutch ware potato sector and its futures market in Amsterdam over the period 1971-2003 reveals that the time-varying optimal hedge ratio decreased from 0.34 in 1971 to 0.24 in 2003. The hedging effectiveness, according to this ratio, is 39\%. These estimates conform better with farmers' interest in using futures contracts for hedging purposes than the much higher estimates obtained when price risk minimisation is the only objective considered.
\end{abstract}

Keywords: agency theory; crop farmers; futures market; hedge ratio; risk.

JEL classifications: $D 81, G 13, L 14, Q 14$.

\section{Introduction}

A futures contract (often referred to as 'futures', for short) is an agreement to deliver a specific amount of a commodity (or other asset) at a specified future time. Futures contracts are standardised, which facilitates their trading on organised exchanges in which the only issue to be negotiated at trading time is the price. As futures contracts are commitments to trade in the future, actual delivery and payment are not required until the contract matures. A primary use of futures involves shifting risk from a firm

\footnotetext{
${ }^{1}$ John K. M. Kuwornu, W. Erno Kuiper and Matthew T. G. Meulenberg are Ph.D. candidate, associate professor and professor emeritus, respectively, Marketing and Consumer Behaviour Group, Wageningen University, The Netherlands. E-mail: Erno.Kuiper@wur.nl for correspondence. Joost M. E. Pennings is an associate professor in the Department of Agricultural and Consumer Economics, Marketing and Decision Sciences Group, University of Illinois at Urbana-Champaign, Urbana, USA; and the AST professor of futures markets in the Marketing and Consumer Behaviour Group, Wageningen University, The Netherlands. We are grateful to two anonymous referees for their helpful comments on an earlier version of this paper.
} 
that desires less risk (the hedger) to a party who is willing to accept the risk in exchange for an expected profit (the speculator). For example, crop farmers can protect themselves from declines in prices of expected outputs by selling futures contracts at the beginning of the growing period and buying back futures at the time their product is ready to be sold in the spot market. As futures and spot prices are positively correlated, losses and gains in the two markets tend to offset each other, leaving the hedger with a return close to what was expected (Working, 1953; Ederington, 1979).

Harvest output uncertainty can reduce the revenue risk reduction capacity of hedging for crop farmers, however, generally making it advisable for them to sell futures for only a fraction of the expected harvest (Moschini and Lapan, 1995). Moreover, although futures and spot prices tend to move in parallel, these movements are not usually identical; this results in basis risk (where 'basis' is defined as the local spot price minus the futures price). As can be demonstrated by the minimum-variance criterion, this is also why the optimal hedge ratio (i.e. the futures position divided by the spot position) can be less than 1. Consequently, for crop farmers and all other traders wishing to reduce risk by hedging with futures contracts, the hedge ratio is of critical importance (Harwood et al., 1999; Dawson et al., 2000).

Much research into improving the estimation of the optimal hedge ratio has been carried out (see Lien and Tse, 2002, for a review). An important result in this respect has been the replacement of the classical regression method (Ederington, 1979), which assumes a time-invariant hedge ratio, by time-varying estimates as permitted in generalized autoregressive conditional heteroscedasticity $(\mathrm{GARCH})$ and stochastic volatility (SV) models. Unfortunately, these GARCH and SV models have two important shortcomings. First, they have little economic content except the notion that 'rational' decision-makers might wish to base their choices on the most current information (changing covariances and variances). In contrast, vertical contractual relationships between crop farmers and agents in other stages of the supply chain determine how much risk the agents bear in each of the stages (Pennings and Wansink, 2004) and hence, each agent's optimal hedge ratio. The principal-agent theory is a widely used economic approach towards modelling these contractual relationships (Eisenhardt, 1989; Milgrom and Roberts, 1992; Furubotn and Richter, 1997). Consequently, in this paper, we use the classic model in agency theory as a starting point for deriving the optimal hedge ratio. To the best of our knowledge, this is the first time that price hedging in the futures market has been viewed within the context of vertical contractual relationships in terms of the principal-agent framework.

A second drawback of GARCH and SV models is that they can usually only be estimated for time-series data recorded at frequencies of 1 day or less. Partly as a consequence of this, these models do not work well, particularly in an out-of-sample context when compared with constant hedge-ratio strategies (Lien and Tse, 2002). High-frequency data such as daily or hourly observations are rarely considered by crop farmers when they have to decide about their production scheme; from the literature it is clear that they base such decisions on an average of prices over a number of years. Supply models with adaptive expectations (see Nerlove, 1958a, b; Askari and Cummings, 1977) illustrate the point.

Related to this, high-frequency data may contain noise that disappears when aggregated to lower frequencies. As they contain less noise, such lower-frequency data could better reveal economic relationships of interest for crop farmers and the management of the futures exchange (see, e.g. Kuiper et al., 2002), such as the relationship between yield variability and the optimal hedge ratio. In this paper, we 
show that the principal-agent model allows for a time-varying hedge ratio to be estimated from these economic relationships of interest.

The outline of the paper is as follows. In Section 2, we derive the model and focus on several relationships of interest. In Section 3, we discuss parameter estimation and model validation. In Section 4, we apply the model to an illustrative data set, and find that the model provides useful insights. Finally, in Section 5, we review our findings and discuss their implications.

\section{Model}

In this section, we outline the classic model in agency theory (see Gibbons, 2005, for a recent discussion). The classic agency model has been widely applied to describe the contractual relationships between the various entrepreneurs in the supply chain of a traded commodity (see Sexton and Lavoie, 2001, for a survey). To derive the optimal hedge ratio, however, we extend the model by having the risk-averse entrepreneurs reduce their risk by hedging with futures contracts.

In what follows, we consider crop farmers who produce a raw farm product which they sell to marketing firms with the help of production contracts offered by the marketing firms. The crop farmers face price risk and output (yield) risk and use futures price contracts to effectively manage their price risk. Given the expected utility maximisation by the crop farmers and the expected profit maximisation by the marketing firms, we derive the optimal hedge ratio for the crop farmers conditional on the parameters in the production contract that are optimal for the marketing firms and acceptable to the crop farmers.

Let the crop farmers be risk-averse decision-makers. A crop farmer does not have full control over the yield, as the yield is vulnerable to the vagaries of nature. Hence, a crop farmer bears the risk of a bad harvest. Nevertheless, s/he may not be the only farmer facing a bad harvest; other farmers could also be hit. If harvest failure is widespread, supply will be limited and prices will be high. Given the inverse relationship between price and quantity supplied, we expect the output value - the product of price and quantity supplied - to vary less than the product of quantity supplied and the price of a fixed-price production contract in which the price is set far before harvest time and hence does not reflect unexpectedly good or bad harvests (cf. Moschini and Lapan, 1995). Therefore, a fixed-price production contract does not rescue the crop farmer from bearing revenue risk.

A contract that bears some relation to the market price, however, is embedded in the following linear function: ${ }^{2}$

$$
w_{t}=\alpha_{t, t-1} x_{t}+\beta_{t, t-1},
$$

where $w_{t}$ is the compensation that the marketing firm pays to the crop farmer in exchange for the produce, $x_{t}$ the output value at consumer prices realised by the marketing firm when selling the crop farmer's produce, $\alpha_{t, t-1}$ the output-value sharing rate fixed in year $t-1$ with respect to the output value in year $t$, as generated by the harvest, the production schedule of which was decided upon in year $t-1$,

\footnotetext{
${ }^{2}$ Linearity is the rule, not the exception, when one examines the contracts that are written in real-world situations (see Holmstrom and Milgrom, 1987, and Bhattacharyya and Lafontaine, 1995, for possible explanations).
} 
and finally, $\beta_{t, t-1}$ represents the fixed payment in year $t$, as established in the contract agreed upon between marketing firm and crop farmer in year $t-1$, at the time the crop farmer drew up her/his production schedule. A mixed share-rent contract is associated with $0<\alpha_{t, t-1}<1$ and $\beta_{t, t-1} \neq 0$.

To simplify the analysis, we consider the marketing firms as the only downstream stage of the supply chain. The model then becomes a two-stage channel, with the crop farmers as the upstream stage and the marketing firms as the downstream stage. The marketing firms are considered to convert the raw farm product into finished consumer goods by performing a set of marketing services, such as collection, cleaning, processing, transportation and retailing. Given that the marketing firms contract the crop farmers, they are the principals in the classic agency model (Furubotn and Richter, 1997; Gibbons, 2005), whereas the crop farmers are the agents. In this model, the principal is assumed to be risk-neutral; for example, many marketing firms have become large companies, enabling them to diversify to spread the risk.

In line with the classic agency model, the linear contract in equation (1) is chosen as it corresponds to real-world settings (Knoeber, 1999; Allen and Lueck, 2002). Moreover, Holmstrom and Milgrom (1987) have shown that the optimal compensation scheme for providing incentives over time to an agent with a constant absolute risk aversion for the duration of the contract is a linear function of the end-ofperiod results, such as revenues, costs or profits. This result is based on the fact that a linear contract provides more uniform incentives than a non-linear contract, as can be seen by viewing the annual output as the outcome of many small daily actions of the agent. Seen from this perspective, a non-linear contract may create unintentional or non-uniform incentives for the agent in the course of the year, depending on the agent's performance to date (Gibbons, 2005).

In equation (1) the output value at consumer prices, $x_{t}$, can be decomposed into two components, of which one is expected and the other is unexpected:

$$
x_{t}=e_{t}+\varepsilon_{t},
$$

where $e_{t}=E\left(x_{t} \mid I_{t-1}\right)$ is the expectation of $x_{t}$, conditional on the information set $I$ as available in year $t-1$, and $\varepsilon_{t}$ is the unexpected part of $x_{t}$ :

$$
E\left(\varepsilon_{t} \mid I_{t-1}\right)=0, \quad \operatorname{var}\left(\varepsilon_{t} \mid I_{t-1}\right)=\sigma_{\varepsilon}^{2} \quad \text { and } \quad \operatorname{cov}\left(\varepsilon_{t}, \varepsilon_{s} \mid I_{t-1}\right)=0,
$$

for all $s \neq t$. All expectations are assumed to be common knowledge among the principal and agent. In turn, the expected output value can be decomposed into price and quantity:

$$
e_{t}=E\left(p_{t} q_{t} \mid I_{t-1}\right)
$$

where $p$ is the consumer price and $q$ is the quantity consumed, assumed to be equal to the quantity produced.

The cost incurred by the agent when producing the output is assumed to be a convex function of the expected output value:

$$
C_{t}=\gamma_{0}+\gamma_{1} t+0.5 c e_{t}^{2},
$$

where $c$ is a positive parameter and the linear time trend represents cost-reducing technical change if $\gamma_{1}<0 .{ }^{3}$ This cost function takes into account that planning more

\footnotetext{
${ }^{3}$ We also performed our analysis with the linear term $e_{t}$ included in the cost function, but when estimating the parameters in equation (24), see Section 3, our empirical data set appeared to be unable to identify the parameters of the linear and quadratic terms as a consequence of collinearity problems.
}

(C) Blackwell Publishing Ltd. 2005 
production (larger expected $q$ ) and a higher quality (higher expected $p$ ) lead to higher cost.

The agent can manage price risk by using the futures market. In year $t-1$, when the production decision is made, a futures contract is sold at price $F_{t, t-1}$ for quantity $z_{t-1}$ which matures in year $t$. In year $t$, the contract is repurchased at the futures price $F_{t, t}$. Hence, the agent's net return for year $t$ is (Yoo and Maddala, 1991):

$$
\pi_{t}=w_{t}-C_{t}+\left(F_{t, t-1}-F_{t, t}\right) z_{t-1},
$$

where we assume that

$$
\begin{gathered}
E\left(F_{t, t-1}-F_{t, t} \mid I_{t-1}\right)=\mu_{F}, \quad \operatorname{var}\left(F_{t, t-1}-F_{t, t} \mid I_{t-1}\right)=\sigma_{F}^{2}, \\
\operatorname{cov}\left(F_{t, t-1}-F_{t, t}, F_{s, s-1}-F_{s, s} \mid I_{t-1}\right)=\operatorname{cov}\left(F_{t, t-1}-F_{t, t}, \varepsilon_{s} \mid I_{t-1}\right)=0
\end{gathered}
$$

for all $s \neq t$ and

$$
\operatorname{cov}\left(F_{t, t-1}-F_{t, t}, \varepsilon_{t} \mid I_{t-1}\right)=\sigma_{\varepsilon F} .
$$

Under the assumptions that the agent's risk preference exhibits constant absolute risk aversion (CARA) and that the agent's net return $\pi_{t}$ is a normally distributed random variable, ${ }^{4}$ the agent maximises the following certainty equivalent of the uncertain net return (Chavas, 2004):

$$
\max _{e_{t}, z_{t, t-1}}\left\{E\left(\pi_{t} \mid I_{t-1}\right)-0.5 \rho_{t} \operatorname{var}\left(\pi_{t} \mid I_{t-1}\right)\right\}
$$

where $\rho_{t}>0$ is the Arrow-Pratt coefficient of absolute risk aversion. From equations (1)-(5) we obtain that

$$
E\left(\pi_{t} \mid I_{t-1}\right)=\alpha_{t, t-1} e_{t}+\beta_{t, t-1}-\gamma_{0}-\gamma_{1} t-0.5 c e_{t}^{2}+\mu_{F} z_{t-1}
$$

and

$$
\operatorname{var}\left(\pi_{t} \mid I_{t-1}\right)=\alpha_{t, t-1}^{2} \sigma_{\varepsilon}^{2}+z_{t-1}^{2} \sigma_{F}^{2}+2 \alpha_{t, t-1} z_{t-1} \sigma_{\varepsilon F} .
$$

Substituting equations (7) and (8) into (6) yields the following first-order condition when maximising for $e_{t}$ :

$$
\alpha_{t, t-1}-c e_{t}=0
$$

and a second-order condition $-c<0$, which conforms with the assumption that $c$ is a positive parameter. Equation (9) is called the incentive constraint and must be satisfied by any feasible contract. Another constraint that must be satisfied is the participation constraint, according to which the certainty equivalent of $\pi_{t}$ equals the agent's reservation wage, a wage that the agent can obtain without risk in an alternative job:

$$
\bar{w}_{t}=E\left(\pi_{t} \mid I_{t-1}\right)-0.5 \rho_{t} \operatorname{var}\left(\pi_{t} \mid I_{t-1}\right),
$$

where $\bar{w}_{t}$ is the agent's reservation wage.

\footnotetext{
${ }^{4}$ For time-series data of low frequency, like annual data, this may be a reasonable assumption; the observation by Moschini and Lapan (1995) that the product of the two random variables 'price' and 'quantity' is generally not normally distributed then applies to higher frequencies.
} 
Solving equation (6) for $z_{t-1}$, which is similar to minimising $\operatorname{var}\left(\pi_{t} \mid I_{t-1}\right)$ if $\mu_{F}=0$, gives the first-order condition

$$
\mu_{F}-\rho_{t} z_{t-1} \sigma_{F}^{2}-\rho_{t} \alpha_{t, t-1} \sigma_{\varepsilon F}=0
$$

and the second-order condition $-\rho_{t} \sigma_{F}^{2}<0$. The hedge ratio is defined as

$$
h_{t}=\frac{z_{t-1}}{E\left(q_{t} \mid I_{t-1}\right)}
$$

where, in the case of a crop, the expected production $E\left(q_{t} \mid I_{t-1}\right)$ is determined by the product of area planted and expected yield per hectare. Solving equation (11) for $z_{t-1}$ and substituting into equation (12) gives the estimate of the optimal hedge ratio as

$$
h_{t}^{*}=\frac{\mu_{F}-\rho_{t} \alpha_{t, t-1} \sigma_{\varepsilon F}}{\rho_{t} \sigma_{F}^{2} E\left(q_{t} \mid I_{t-1}\right)} .
$$

The expression for $h_{t}^{*}$ in equation (13) reduces to 0 if $\mu_{F}=\sigma_{\varepsilon F}=0$; i.e. the discount rate is zero $\left(\mu_{F}=0\right)$ and the futures price is indifferent to variations in output value $\left(\sigma_{\varepsilon F}=0\right)$. Moreover, $h_{t}^{*}$ also tends to zero if $\sigma_{F}^{2}$ becomes very large. If, however, $\rho_{t}$ becomes very large, then from equations (12) and (13) it appears that $z_{t-1}$ goes to $-\alpha_{t, t-1} \sigma_{\varepsilon F} / \sigma_{F}^{2}$ (hence, we expect $\sigma_{\varepsilon F}<0$ ), which is -1 times the output-value sharing rate times the estimated coefficient of $\left(F_{t, t-1}-F_{t, t}\right)$ in the linear regression of $\varepsilon_{t}$ on a constant and $\left(F_{t, t-1}-F_{t, t}\right)$. Before $h_{t}^{*}$ can be estimated by equation (13), we need to solve the profit maximisation problem of the principal.

In this two-stage game, the principal maximises his/her expected payoff in the second stage of the game, while anticipating the behaviour of the agent in the first stage of the game as described above:

$$
\max \left\{E\left(x_{t}-w_{t} \mid I_{t-1}\right)\right\}=\max \left\{\left(1-\alpha_{t, t-1}\right) e_{t}-\beta_{t, t-1}\right\}
$$

where the expression on the right-hand side results from equation (1) and (2). Taking into account the incentive constraint (9), the participation constraint (10), and the agent's optimal futures position as implied by equation (11), the principal knows:

$$
\begin{gathered}
e_{t}=\frac{\alpha_{t, t-1}}{c} \\
\beta_{t, t-1}=\bar{w}_{t}-\alpha_{t, t-1} e_{t}+\gamma_{0}+\gamma_{1} t+0.5 c e_{t}^{2}-\mu_{F} z_{t-1} \\
+0.5 \rho_{t}\left(\alpha_{t, t-1}^{2} \sigma_{\varepsilon}^{2}+z_{t-1}^{2} \sigma_{F}^{2}+2 \alpha_{t, t-1} z_{t-1} \sigma_{\varepsilon F}\right) \\
z_{t-1}=\frac{\mu_{F}-\rho_{t} \alpha_{t, t-1} \sigma_{\varepsilon F}}{\rho_{t} \sigma_{F}^{2}}
\end{gathered}
$$

Substituting equation (16) in (14) and then substituting equations (15) and (17) for $e_{t}$ and $z_{t-1}$, respectively, gives 


$$
\begin{gathered}
\max _{\alpha_{t, t-1}}\left\{\frac{\alpha_{t, t-1}}{c}-\bar{w}_{t}-\frac{0.5 \alpha_{t, t-1}^{2}}{c}-\gamma_{0}-\gamma_{1}^{t}+\frac{\mu_{F}^{2}-\rho_{t} \alpha_{t, t-1} \sigma_{\varepsilon F} \mu_{F}}{\rho_{t} \sigma_{F}^{2}}-0.5 \rho_{t} \alpha_{t, t-1}^{2} \sigma_{\varepsilon}^{2}\right. \\
\left.-\frac{0.5\left(\mu_{F}-\rho_{t} \alpha_{t, t-1} \sigma_{\varepsilon F}\right)^{2}}{\rho_{t} \sigma_{F}^{2}}-\frac{\alpha_{t, t-1} \sigma_{\varepsilon F} \mu_{F}-\rho_{t} \alpha_{t, t-1}^{2} \sigma_{\varepsilon F}^{2}}{\sigma_{F}^{2}}\right\}
\end{gathered}
$$

of which the first-order condition is

$$
\frac{1}{c}-\frac{\sigma_{\varepsilon F} \mu_{F}}{\sigma_{F}^{2}}-\left(\frac{1}{c}+\rho_{t} \sigma_{\varepsilon}^{2}-\frac{\rho_{t} \sigma_{\varepsilon F}^{2}}{\sigma_{F}^{2}}\right) \alpha_{t, t-1}=0
$$

and the second-order condition imposes $-\left(1 / c+\rho_{t} \sigma_{\varepsilon}^{2}-\rho_{t} \sigma_{\varepsilon F}^{2} / \sigma_{F}^{2}\right)<0$.

Solving equation (19) for $\alpha_{t, t-1}$ we obtain, after some rewriting:

$$
\alpha_{t, t-1}=\frac{1-c \sigma_{\varepsilon F} \mu_{F} / \sigma_{F}^{2}}{1+c \rho_{t}\left(\sigma_{\varepsilon}^{2} \sigma_{F}^{2}-\sigma_{\varepsilon F}^{2}\right) / \sigma_{F}^{2}} .
$$

Equation (20), known as the incentive intensity principle, shows that under the condition that $\alpha_{t, t-1}$ must be between zero (full insurance) and one (full incentive), the more risk averse the agent is, the smaller $\alpha_{t, t-1}$ becomes $\left(\rho_{t}\right.$ is higher, implying that $\sigma_{\varepsilon}^{2} \sigma_{F}^{2}>\sigma_{\varepsilon F}^{2}$ ). Furthermore, if $\sigma_{\varepsilon F}=0$, then equation (20) reduces to

$$
\alpha_{t, t-1}=\frac{1}{1+c \rho_{t} \sigma_{\varepsilon}^{2}},
$$

in which case $\alpha_{t, t-1}$ diminishes if the marginal cost of effort increases more quickly ( $c$ is higher), or if there is more uncertainty in output value ( $\sigma_{\varepsilon}^{2}$ is higher). Substituting equation (20) in (13) leads to the following expression for the optimal hedge ratio:

$$
h_{t}^{*}=\frac{\mu_{F}\left(1 / \rho_{t}+c \sigma_{\varepsilon}^{2}\right)-\sigma_{\varepsilon F}}{\left[\sigma_{F}^{2}+c \rho_{t}\left(\sigma_{\varepsilon}^{2} \sigma_{F}^{2}-\sigma_{\varepsilon F}^{2}\right)\right] E\left(q_{t} \mid I_{t-1}\right)},
$$

which includes the time-varying components $\rho_{t}$ and $E\left(q_{t} \mid I_{t-1}\right)$ so that the optimal hedge ratio can be expected to vary over time.

So, a rational principal determines the optimal values of the contract parameters $\alpha_{t, t-1}$ according to equation (20) and, subsequently, $\beta_{t, t-1}$ according to equation (16) after substituting equations (15) and (17). This implies that not only the agent but also the principal is assumed to know the values of $c, \sigma_{\varepsilon F}, \mu_{F}, \sigma_{F}^{2}$, $\rho_{t}, \sigma_{\varepsilon}^{2}, \bar{w}_{t}, \gamma_{0}$, and $\gamma_{1}$. In the next section, we discuss how we can estimate these values empirically in order to assess the validity of the model for ascertaining the optimal hedge ratio.

\section{Econometric Issues and Data Requirements}

We now describe the data we used to estimate the parameters for determining the optimal hedge ratio. Note that all prices - whether spot prices or futures prices - are deflated by the consumer price index. The fit of the regression of the consumer price 
$p_{t}$ on a constant and the futures price $F_{t, t-1}$ gives us the estimate of $E\left(p_{t} \mid I_{t-1}\right) .{ }^{5} \mathrm{We}$ will replace $E\left(p_{t} \mid I_{t-1}\right)$ by this estimate, denoted as $\hat{E}\left(p_{t} \mid I_{t-1}\right)$. Using data on yield per hectare and the number of hectares planted, the estimate of $E\left(q_{t} \mid I_{t-1}\right)$, denoted as $\hat{E}\left(q_{t} \mid I_{t-1}\right)$, is obtained by the product of area planted and expected yield per hectare, where the expected yield per hectare is assumed to be an autonomous positive linear time trend. Next, we turn to the estimation of $e_{t}=E\left(p_{t} q_{t} \mid I_{t-1}\right)$. For this, note that

$$
p_{t} q_{t}=E\left(p_{t} \mid I_{t-1}\right) E\left(q_{t} \mid I_{t-1}\right)+E\left(p_{t} \mid I_{t-1}\right) \varepsilon_{q t}+\varepsilon_{p t} E\left(q_{t} \mid I_{t-1}\right)+\varepsilon_{p t} \varepsilon_{q t},
$$

where

$$
\varepsilon_{p t}=p_{t}-E\left(p_{t} \mid I_{t-1}\right) \quad \text { and } \quad \varepsilon_{q t}=q_{t}-E\left(q_{t} \mid I_{t-1}\right)
$$

are the unexpected components of $p_{t}$ and $q_{t}$, respectively, and $\varepsilon_{p t} \varepsilon_{q t}$ represents the covariance of $p_{t}$ and $q_{t}$, which we expect to be negative. Consequently,

$$
E\left(p_{t} q_{t} \mid I_{t-1}\right)=E\left(p_{t} \mid I_{t-1}\right) E\left(q_{t} \mid I_{t-1}\right)+E\left(\varepsilon_{p t} \varepsilon_{q t} \mid I_{t-1}\right) .
$$

Now, to estimate $E\left(p_{t} q_{t} \mid I_{t-1}\right)$ we simply regress $p_{t} q_{t}$ on a constant and $\hat{E}\left(p_{t} \mid I_{t-1}\right) \times$ $\hat{E}\left(q_{t} \mid I_{t-1}\right)$. In this way, $\hat{E}\left(p_{t} \mid I_{t-1}\right) \hat{E}\left(q_{t} \mid I_{t-1}\right)$ extracts all the information of interest out of $\varepsilon_{p t} \varepsilon_{q t}$ since the regression residuals are orthogonal to $\hat{E}\left(p_{t} \mid I_{t-1}\right) \hat{E}\left(q_{t} \mid I_{t-1}\right)$. Hence, the fit of the regression is denoted as $\hat{E}\left(p_{t} q_{t} \mid I_{t-1}\right)=\hat{e}_{t}$.

To continue, the estimate of $\varepsilon_{t}$, denoted as $\hat{\varepsilon}_{t}$, is obtained by subtracting $\hat{E}\left(p_{t} q_{t} \mid I_{t-1}\right)$ from $p_{t} q_{t}$. The variance of $\hat{\varepsilon}_{t}$ is the estimate of $\sigma_{\varepsilon}^{2}$, denoted as $\hat{\sigma}_{\varepsilon}^{2}$. Similarly, using the data on $F_{t, t-1}$ and $F_{t, t}$ it is straightforward to obtain the estimates of $\sigma_{\varepsilon F}, \mu_{F}$ and $\sigma_{F}^{2}$, denoted as $\hat{\sigma}_{\varepsilon F}, \hat{\mu}_{F}$ and $\hat{\sigma}_{F}^{2}$, respectively. Finally, as we also have data on $\bar{w}_{t}$, the only other estimates we need in order to be able to compute the optimal hedge ratio are those of $\rho_{t}$ and $c$.

To estimate $\rho_{t}$ and $c$, we first consider the incentive constraint in equation (9) and the incentive intensity in equation (20). Solving equation (9) for $\alpha_{t, t-1}$, substituting this solution for $\alpha_{t, t-1}$ in equation (20) and inserting the values that have already been estimated, we arrive at the following solution for $\rho_{t}$ :

$$
\rho_{t}=\frac{\hat{\sigma}_{F}^{2}-c\left(\hat{e}_{t} \hat{\sigma}_{F}^{2}+\hat{\sigma}_{\varepsilon F} \hat{\mu}_{F}\right)}{c^{2} \hat{e}_{t}\left(\hat{\sigma}_{F}^{2} \hat{\sigma}_{\varepsilon}^{2}-\hat{\sigma}_{\varepsilon F}^{2}\right)} .
$$

Next, we substitute equation (23) together with the solution for $\alpha_{t, t-1}$ into equation (11) to solve for $z_{t-1}$. Subsequently, the solutions for $\alpha_{t, t-1}, \rho_{t}$ and $z_{t-1}$ are inserted into equation (16) and both the resulting expression for $\beta_{t, t-1}$ and the solution for $\alpha_{t, t-1}$ are then substituted in equation (1), yielding

$$
\begin{aligned}
w_{t}-\bar{w}_{t}-0.5 \hat{e}_{t}= & \gamma_{0}+\gamma_{1} t+c \hat{e}_{t}\left(x_{t}-\hat{e}_{t}+0.5 \hat{\sigma}_{\varepsilon F} \hat{\mu}_{F} / \hat{\sigma}_{F}^{2}\right) \\
& -\frac{0.5 c^{2} \hat{e}_{t}\left(\hat{\mu}_{F}^{2} / \hat{\sigma}_{F}^{2}\right)\left(\hat{\sigma}_{F}^{2} \hat{\sigma}_{\varepsilon}^{2}-\hat{\sigma}_{\varepsilon F}^{2}\right)}{\hat{\sigma}_{F}^{2}-c\left(\hat{e}_{t} \hat{\sigma}_{F}^{2}+\hat{\sigma}_{\varepsilon F} \hat{\mu}_{F}\right)} .
\end{aligned}
$$

Apart from the $\gamma$ parameters in the deterministic part of equation (24), the only unknown parameter in the equation is $c$. We estimate $\gamma_{0}, \gamma_{1}$ and $c$ in equation (24)

\footnotetext{
${ }^{5}$ Note that $p$ is the consumer (i.e. retail) price while $F$ concerns the futures notation of the farm price. Nevertheless, since we are working with annual data, not with data of a higher frequency such as monthly or weekly observations, we do not expect to observe any asymmetric price transmission between farmers and retailers. (For a review of asymmetric price transmission, see Meyer and von Cramon-Taubadel, 2004.)
} 
by non-linear least squares ${ }^{6}$ and then substitute the estimate of $c$, denoted as $\hat{c}$, in equation (23) to obtain the estimate of $\rho_{t}$, denoted as $\hat{\rho}_{t}{ }^{7}$ and in equation (9) to solve for $\alpha_{t, t-1}$, denoted as $\hat{\alpha}_{t, t-1}$. Finally, we use all these estimates in equation (11) to solve for $z_{t-1}$, denoted as $\hat{z}_{t-1}$. In this way, we obtain the optimal hedge ratio in equation (12) [cf. equation (13)]. Using equation (16), we can now also obtain an estimate for $\beta_{t, t-1}$, denoted as $\hat{\beta}_{t, t-1}$, which allows us to compare the model estimates $\hat{\alpha}_{t, t-1} x_{t}+\hat{\beta}_{t, t-1}$ with the actual values of $w_{t}$ [see equation (1), to evaluate the model's validity for determining the optimal hedge ratio]. In this respect, we can test for the normality assumption regarding $\pi_{t}$ as well.

\section{Empirical Illustration}

Every year, some eight million tonnes of potatoes are produced in the Netherlands, mainly on family farms. About half are ware potatoes, approximately $20 \%$ are seed potatoes, while the remaining $30 \%$ are potatoes grown for starch. We focus on the ware potatoes.

There is very little interference in the free market for ware potatoes in the Netherlands and hence 'outside' involvement is minimal (Young, 1977; Smidts, 1990). Nevertheless, most ware potatoes are sold to wholesalers, and most of the wholesale trade has become concentrated in relatively few hands, as the major users - particularly the large retailers, processors and export markets - demand large quantities with tight specifications that only the larger wholesalers can meet. In response to this development in the market, the need has arisen to procure potatoes before harvest. Various approaches have emerged, the most important being fixed price contracts and pooling contracts. These contractual forms are well nested in the linear contract of the classic agency model. ${ }^{8}$

The fixed-price contract involves selling a net amount of potatoes at a fixed contract price. This marketing strategy entails transferring the entire price risk from the farmer to the marketing firm. In the pooling-contract system, potatoes supplied by

\footnotetext{
${ }^{6}$ Note that the estimation equation includes regressors that are estimates themselves. Nevertheless, these estimates are not obtained by the fit of extensive regressions and hence, in order to overcome the 'generated regressors' problem (see Pagan, 1984), we cannot jointly estimate these regressions in a simultaneous model with equation (24) by Full Information Maximum Likelihood (FIML). Therefore, our results may be vulnerable to the error-in-variables problem, although footnote 11 shows that our estimate of $c$ seems to be quite consistent.

${ }^{7}$ This section is about estimation and so is equation (23). Consequently, equation (23) must be considered as a way to estimate rather than to explain $\rho$ by the data we observe, as these data are generally considered to be affected by the intrinsically behavioural parameter $\rho$ (and hence, contain information about its actual value) instead of the other way around. In fact, according to the CARA assumption, $\rho$ is a constant for all $e$, i.e. $e$ does not cause $\rho$ but $\rho$ causes $e$ as can be seen from equation (15) and (20). Consequently, $e$ is a function of $\rho$, say $e=f(p)$, and hence, equation (23) must be seen as $\rho=f^{-1}(e)$ for estimation purposes.

${ }^{8}$ If a farmer sells a relatively large part of her/his harvest through a fixed price contract at the time that $\mathrm{s} /$ he makes her/his decision about what and how much to plant, then this can be represented by a lower value of $\alpha_{t, t-1}$ and a higher value of $\beta_{t, t-1}$ in equation (1). As a consequence of the lower value for $\alpha_{t, t-1}$ we can see from equation (17) that $z_{t-1}$ will become smaller (and hence, $h_{t}^{*}$ ) given that $\sigma_{\varepsilon F}$ is smaller than zero [see also the discussion below equation (13)].
} 
the farmers are sold by wholesalers throughout the year. The resulting gross returns from these sales, minus the wholesalers' expenses, are distributed across the farmers, in proportion to the amount of potatoes delivered. The reason non-fixed price arrangements have been adopted is because wholesalers wish to retain their core suppliers by offering them contracts that bear some relation to the market price, as these suppliers can use the potato futures contract of the Amsterdam Exchanges 9 for hedging purposes (see Kuiper et al., 2002), and for price discovery.

The annual data used for our research cover the period 1971-2003 and were obtained from Statistics Netherlands and Euronext. ${ }^{10}$ They include the farm and retail prices (euro $/ \mathrm{kg}$ ) of ware potatoes, both deflated by the consumer price index $(1990=1.00)$; the area planted $(1000 \mathrm{ha})$ and the yield per hectare $(100 \mathrm{~kg})$. As a proxy for $\bar{w}_{t}$, we multiplied the area planted by the rent price of land (euro/ha) deflated by the consumer price index. We used the futures price (euro $/ \mathrm{kg}$ ) for delivery in April of year $t$ quoted as the closing price of the first trading day of April in year $t-1$ to represent $F_{t, t-1}$; to represent $F_{t, t}$, we used that price quoted as the closing price of the first trading day of November (when most potatoes are sold by the farmers) in year $t-1$. Both $F_{t, t-1}$ and $F_{t, t}$ are deflated by the consumer price index as well. From these data, we derived the variables and parameters of interest as described in the previous section, in order to estimate the optimal hedge ratio for the Dutch case along the lines of the principal-agent model. ${ }^{11}$ Table 1 provides some descriptive statistics of the time series used.

The results of estimating equation (24) by non-linear least squares are displayed in Table 2. The estimate of $c$ equals $0.44 .{ }^{12}$ Computing $\hat{\alpha}_{t, t-1}$ along the lines of equation (9), that is $\hat{\alpha}_{t, t-1}=\hat{c} \hat{e}_{t}$ while using $\hat{c}=0.44$, yields values that increase within a range of 0.37 and 0.61 . These estimated values support the theoretical restriction $0 \leq \alpha_{t, t-1} \leq 1$. Moreover, substituting $\hat{c}=0.44$ in equation (23) yields feasible (i.e. positive) values for $\hat{\rho}_{t}$ decreasing from 90 in 1971 to 50 in 2003 according to a decreasing convex curve, indicating diminishing average risk aversion among producers. The graph of $\hat{\rho}_{t}$ has quite a smooth pattern: note the absence of many short-term fluctuations around the curve that would have detracted from the credibility of the model that allows this coefficient to vary through time for the 'same farmer'. Moreover, observe that the negative coefficient of the linear trend (i.e. the estimate of $\gamma_{1}$ ) is consistent with the cost-reducing technological advances in agriculture.

\footnotetext{
${ }^{9}$ The Amsterdam Exchange used to be called AEX, but in 2000 it was merged with exchanges in Brussels, London, Lisbon and Paris, creating Euronext.

${ }^{10}$ The data are available from the authors upon request.

${ }^{11} F_{t, t-1}$ appears to be an optimal forecast of the farm price $p_{t}^{f}$ in the sense that $\delta_{0}=0$ and $\delta_{1}=1$ in the 'Mincer-Zarnowitz regression' Realisation ${ }_{t}=\delta_{0}+\delta_{1}$ Forecast $_{t}+u_{t}$ (see, e.g. Diebold, 1998, p. 342) with an $R^{2}$ of 0.25 . The regression of the consumer price on a constant and the farm price yields an $R^{2}$ of 0.60 and, after omitting the outlying observations in 1976, 1984 and 1998, the regression of $p_{t} q_{t}$ on a constant and $\hat{E}\left(p_{t} \mid I_{t-1}\right) \hat{E}\left(q_{t} \mid I_{t-1}\right)$ has an $R^{2}$ of 0.61 .

${ }^{12}$ An estimate of 0.50 is obtained if we rewrite the model in (24) as a conditional error-correction model (cf. Boswijk, 1994). Note that the estimate of $c$ in Table 2 does not differ significantly from this super-consistent cointegrating parameter estimate, which shows that the results remain the same, regardless of whether trend stationarity or difference stationarity are chosen.
} 
Table 1

Descriptive statistics of time series variables used regarding Dutch ware potatoes for the sample period 1971-2003 (33 observations)

\begin{tabular}{lrrrrrr}
\hline Variable & Mean & Med & Max & Min & SD & CV \\
\hline$p_{t}$ & 0.39 & 0.37 & 0.89 & 0.26 & 0.11 & 28 \\
$p_{t}^{\mathrm{f}}$ & 0.12 & 0.10 & 0.37 & 0.04 & 0.08 & 68 \\
$F_{t, t}$ & 0.17 & 0.14 & 0.44 & 0.05 & 0.10 & 61 \\
$F_{t, t-1}$ & 0.14 & 0.14 & 0.21 & 0.08 & 0.04 & 27 \\
$p_{t}^{l}$ & 250.00 & 248.00 & 302.00 & 213.00 & 20.70 & 8 \\
$a_{t}$ & 70.60 & 70.60 & 86.10 & 52.30 & 9.22 & 13 \\
$y_{t}$ & 422.00 & 415.00 & 531.00 & 310.00 & 59.10 & 14 \\
$q_{t}$ & 2.97 & 2.96 & 4.46 & 1.72 & 0.75 & 25 \\
$x_{t}$ & 1.12 & 1.03 & 1.96 & 0.72 & 0.30 & 26 \\
$e_{t}$ & 1.12 & 1.14 & 1.37 & 0.85 & 0.15 & 14 \\
$w_{t}$ & 0.34 & 0.28 & 0.80 & 0.13 & 0.19 & 57 \\
$\bar{w}_{t}$ & 0.02 & 0.02 & 0.03 & 0.01 & 0.00 & 19 \\
\hline
\end{tabular}

Notes: Med: median; Max: maximum; Min: minimum; SD: standard deviation; CV: coefficient of variation $\left(=100 \times \mathrm{SD} /\right.$ mean); $p_{t}$ : retail price (weighted average per year in $€ / \mathrm{kg}$ ) divided by the consumer price index $(1990=1.00)$; $p_{t}^{\mathrm{f}}$ : farm price (weighted average per harvest year running from August in year $t-1$ to May in year $t$ in $€ / \mathrm{kg}$ ) divided by the consumer price index $(1990=1.00) ; F_{t, t}$ : futures price for delivery in April of year $t$ quoted as the closing price of the first trading day of November in year $t-1(€ / \mathrm{kg})$ divided by the consumer price index $(1990=1.00) ; F_{t, t-1}$ : futures price for delivery in April of year $t$ quoted as the closing price of the first trading day of April in year $t-1(€ / \mathrm{kg})$ divided by the consumer price index $(1990=1.00) ; p_{t}^{1}$ : rent price of land (weighted average per year in $€ /$ ha) divided by the consumer price index $(1990=1.00) ; a_{t}$ : area planted $(\times 1000 \mathrm{ha}) ; y_{t}$ : yield per hectare $(\times 100 \mathrm{~kg}) ; q_{t}$ : quantity produced $\left(\times 10^{9} \mathrm{~kg}\right)\left(=a_{t} y_{t} / 10^{4}\right) ; x_{t}$ : retail output value $\left(\times 10^{9} €\right)$ $\left(=p_{t} q_{t}\right) ; e_{t}$ : expected retail output value $\left(\times 10^{9} €\right) ; w_{t}$ : farm output value $\left(\times 10^{9} €\right)\left(=p_{t}^{\mathrm{f}} q_{t}\right)$; $\bar{w}_{t}$ : rent value of the land used $\left(\times 10^{9} €\right)\left(=p_{t}^{1} a_{t} / 10^{6}\right)$.

Table 2

Parameter estimates of the cost function as estimated in equation (24)

\begin{tabular}{lcccr}
\hline Parameter & Estimate & Std. error & $t$-Value & $p$-Value \\
\hline$\gamma_{0}$ & -0.024 & 0.047 & -0.511 & 0.613 \\
$\gamma_{1}$ & -0.013 & 0.002 & -5.397 & 0.000 \\
$c$ & 0.441 & 0.079 & 5.615 & 0.000 \\
\hline
\end{tabular}

Sample: $1971-2003$; number of observations $=33 ; R^{2}=0.64 ; R_{\mathrm{adj}}^{2}=0.62 ;$ std. error resid. $=0.13$; sum squared resid. $=0.53$; Durbin - Watson $=1.79$.

Using the estimates of $c, \alpha_{t, t-1}$ and $\rho_{t}$, we can solve for $z_{t-1}$ in equation (17) to obtain estimates of the optimal hedge ratio in equation (13). From Figure 1, which shows these estimates of $\hat{h}_{t}^{*}$, it is clear that the ratio varies over time, decreasing from 0.34 in 1971 to 0.24 in 2003 . Measuring risk by $\operatorname{var}\left(\pi_{t} \mid I_{t-1}\right)$ [see equation (8)], the average risk reduction over the sample period when $\hat{z}_{t-1}=\hat{h_{t}^{*}} \hat{E}\left(q_{t} \mid I_{t-1}\right)$ is used instead of the highest (lowest) hedge ratio, giving 


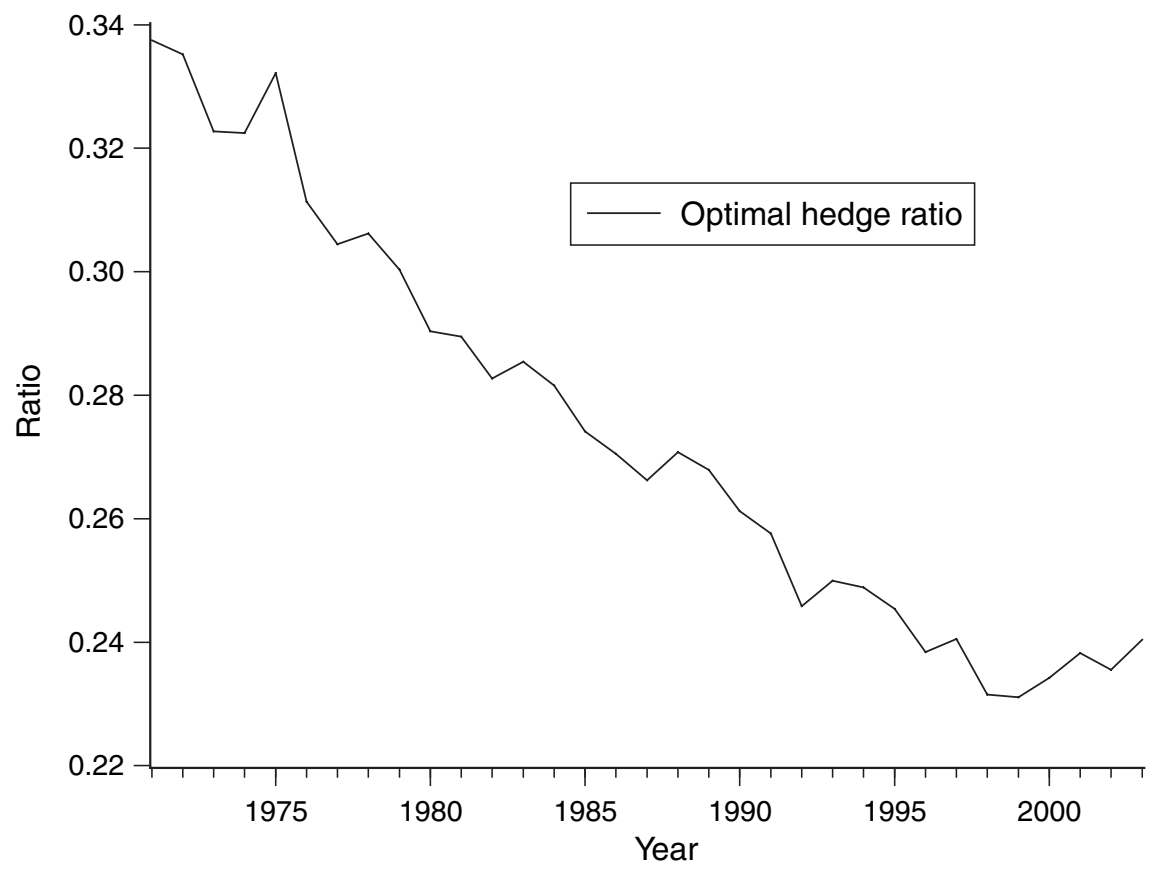

Figure 1. Principal-agent model estimate of the optimal hedge ratio for the Dutch ware potato sector hedging on the futures market in Amsterdam.

$$
\hat{z}_{t-1}=0.34 \hat{E}\left(q_{t} \mid I_{t-1}\right) \quad\left(\hat{z}_{t-1}=0.24 \hat{E}\left(q_{t} \mid I_{t-1}\right)\right),
$$

appears to be $2.46 \%(2.04 \%)$. As a measure of hedging effectiveness, we find that the average risk reduction when using $\hat{z}_{t-1}=\hat{h}_{t}^{*} \hat{E}\left(q_{t} \mid I_{t-1}\right)$ instead of no hedging at all is quite stable at $38.99 \%$ (minimum $=38.89 \%$; maximum $=39.07 \%$ ).

To compare our estimates of the optimal hedge ratio with the common price risk minimising hedge ratio (Ederington, 1979), we utilise equations (1) and (17). We can derive the price risk minimising hedge ratio, $h_{p}$, from equation (17) while using (1) if we assume that the discount rate is zero $\left(\mu_{F}=0\right)$, that the output-value sharing rate, $\alpha_{t, t-1}$, is equal to one and that there is no yield risk. It follows that the time-invariant version of $h_{p}$ can simply be computed as the estimated coefficient of $\left(F_{t, t}-F_{t, t-1}\right)$ in a regression of $\left(p_{t}^{f}-F_{t, t-1}\right)$ on a constant and $\left(F_{t, t}-F_{t, t-1}\right)$, where $p_{t}^{f}$ is the farm price in the spot market (see also Table 1 and footnote 10). The estimate of $h_{p}$ appears to be 0.73 (std. error $=0.05 ; t$-value $=12.60$ ), yielding a hedging effectiveness of $84 \%$ ( $R^{2}$ of the regression). The price risk minimizing hedge ratio $h_{p}$ and the corresponding hedging effectiveness are higher than the ones obtained by our model. This can be explained by the fact that our model, in contrast to the price risk minimising hedging framework, does take into account yield risk [reducing $\sigma_{\varepsilon F}$ in equation (17)] and the competition of alternative risk management instruments like fixed-price contracts [reducing $\alpha_{t, t-1}$ in equation (17)]. Consequently, $h_{t}^{*}$ may provide a better understanding of farmers' hedging behaviour (e.g. their limited use of futures markets).

To check the validity of the model that we used to estimate the optimal hedge ratios shown in Figure 1, we compare the actual payment to the farmer with the 


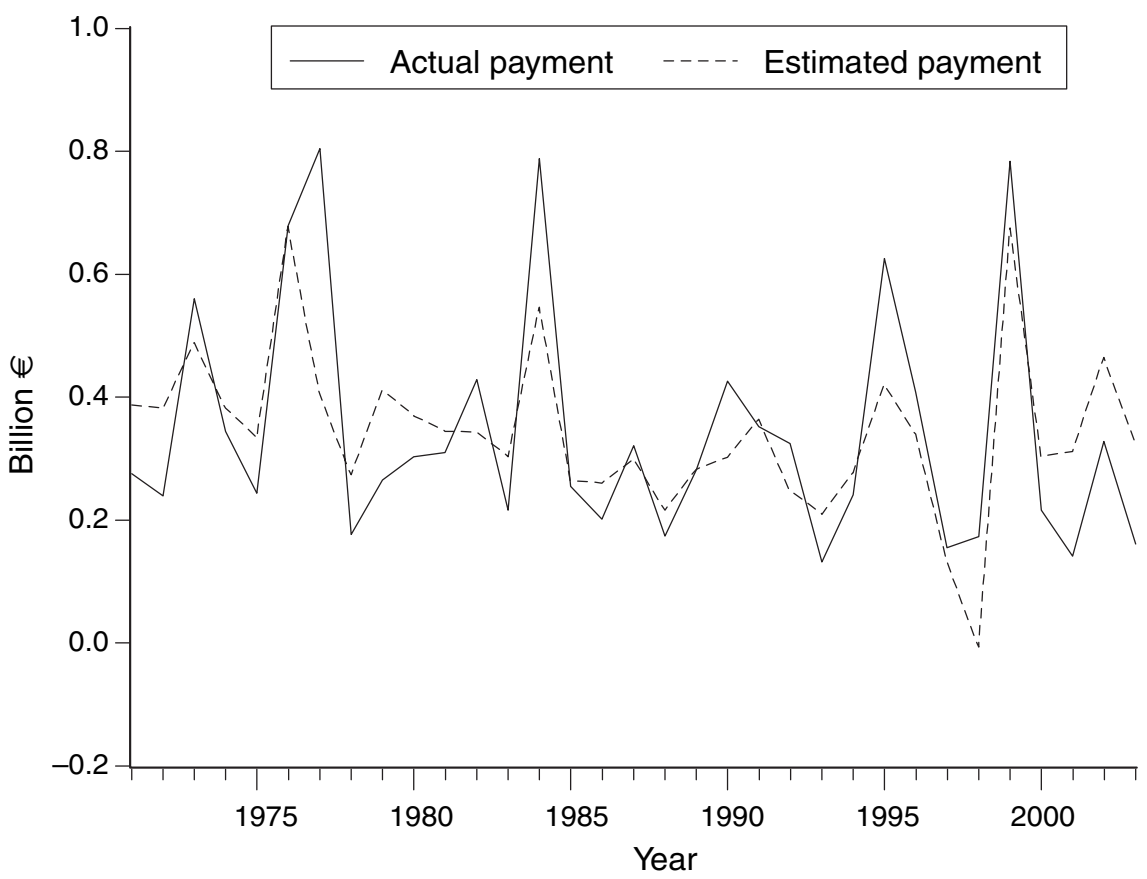

Figure 2. Payment to the farmers: Actual $\left(w_{t}\right)$ and estimated $\left(\hat{\alpha}_{t, t-1} x_{t}+\hat{\beta}_{t, t-1}\right)$.

Table 3

Parameter estimates in the regression of the actual payment $\left(w_{t}\right)$ on the variable and fixed compensation components estimated by the agency model

\begin{tabular}{lccrc}
\hline Variable & Estimate & Std. error & $t$-Value & $p$-Value \\
\hline Intercept & -0.061 & 0.078 & -0.786 & 0.438 \\
$\hat{\alpha}_{t, t-1} x_{t}$ & 1.134 & 0.180 & 6.289 & 0.000 \\
$\hat{\beta}_{t, t-1}$ & 1.068 & 0.191 & 5.598 & 0.000 \\
\hline
\end{tabular}

Sample: $1971-2003$; number of observations $=33 ; R^{2}=0.58 ; R_{\text {adj }}^{2}=0.55 ;$ std. error resid. $=0.13$; sum squared resid. $=0.51$; Durbin - Watson $=1.73$.

payment estimated by the model (see Figure 2) The estimated value explains $57 \%$ of the variance in the actual payment, and is unbiased and significant, as we can see from performing a regression of $w_{t}$ on a constant, $\hat{\alpha}_{t, t-1} x_{t}$ and $\hat{\beta}_{t, t-1}$ (see Table 3 ). In this regression we cannot reject the joint hypothesis of a zero constant and unit coefficients of both $\hat{\alpha}_{t, t-1} x_{t}$ and $\hat{\beta}_{t, t-1}(p$-value $=0.88)$. Finally, testing for the normality of $\pi_{t}$ by using the proxy

$$
\hat{\pi}_{t}=w_{t}-\hat{C}_{t}+\left(F_{t, t-1}-F_{t, t}\right) \hat{z}_{t-1} \quad \text { with } \hat{C}_{t}=\hat{\gamma}_{0}+\hat{\gamma}_{1} t+0.5 \hat{c} \hat{e}_{t}^{2},
$$

while omitting two outlying observations, also leads to non-rejection ( $p$-value JarqueBera statistic $=0.16$ ). 


\section{Concluding Remarks}

For many crops, farmers' production decisions must be based on the output prices and yield per hectare anticipated in a year's time. Consequently, crop farmers base their production decisions on an average of prices over a number of years, rather than on the price obtained on a single trading day. Therefore, a model that considers time series at an annual frequency might be of particular interest for farmers who wish to estimate the optimal hedge ratio. Furthermore, the farmers' hedging decisions will be influenced by the contractual relationships the farmers have with other channel members (Pennings and Wansink, 2004). The classic agency framework allows us to derive a time-varying optimal hedge ratio taking account of both the crop farmer decision structure (using the average price over a number of years) and his/her contractual relationships in the commodity marketing channel.

In our empirical application of the model to the Dutch ware potato sector's futures market in Amsterdam for 1971-2003, the optimal hedge ratio decreases from 0.34 in 1971 to 0.24 in 2003 . Although the hedge ratio clearly varies with time, working with a constant hedge ratio of 0.34 or 0.24 reduces the average risk reduction by only $2.46 \%$ and $2.04 \%$, respectively vis-à-vis the risk reduction obtained by the time-varying ratio. Nevertheless, compared with non-hedging, the average risk reduction by hedging is a stable $38.99 \%$ over the whole sample period (1971-2003), showing the usefulness of the futures market as a risk-management instrument in the Dutch ware potato sector over the last three decades.

The reported hedge ratios in $1995(0.25)$ and $1996(0.24)$ are clearly lower than the ratios reported in Pennings and Meulenberg (1997), who used weekly data on the basis of which they estimated an optimal hedge ratio in a meanvariance framework for Dutch potato growers of 0.47 for 1995 and 1996. This difference is attributable to the fact that their mean-variance model dealt only with price risk. Furthermore, futures markets more often offer the opportunity to hedge against price risk rather than against output value risk, yet - as is captured by the agency model that we propose - it is the latter risk that the farmers must deal with as well. Our estimate of 0.73 for the price risk minimising hedge ratio obtained on the basis of annual data over the period 1971-2003 confirms the result that higher hedge ratios are obtained if only price risk is considered.

Although the contracts established between farmers and other market participants in the marketing channel may not be identical to those in our model, most contracts do have a fixed (sometimes implicit) and variable (incentive) component. Examples can be found in European agriculture in the dairy sector and horticulture industry, where farmers receive a baseline compensation plus a variable compensation based on certain quality and quantity indicators. Furthermore, farmers who are members of a cooperative, as are many Dutch potato growers, have 'contracts' of a type very similar to that described in our paper (Cook, 1995; Fulton and Giannakas, 2001). Our model may be expanded to include some of the idiosyncratic characteristics of contracts in agriculture. Such work could then be used to explain individual differences in farmers' risk behaviour (Pennings and Garcia, 2004).

Our paper has two implications for extension economists. First, it provides a tool (a method) to analyse and determine optimal hedge ratios that account for the fact that the time horizon of farmers, and hence the relevant decision context, is an 
annual one. Although various authors have calculated hedging ratios using weekly or monthly hedge time horizons, this time horizon does not reflect farmers' actual decision making structure. Furthermore, our study takes into account the fact that farmers do not make decisions in isolation, but that they are part of a marketing channel. Their relationship with other channel partners, by means of contracts, influences their optimal hedging behaviour.

Our analysis has been performed on the basis of the implicit assumption of a representative farmer. Furthermore, although the annual frequency of the data we considered in our study is consistent with the fact that agricultural production is a lengthy process, there may be large differences in performance among crop farmers and hence in their individual optimal hedge ratios. There is therefore a clear need for further research on time-series data at the farm level.

\section{References}

Allen, D. W. and Lueck, D. The Nature of the Farm: Contracts, Risk, and Organization in Agriculture (Cambridge, MA: MIT Press, 2002).

Askari, H. and Cummings, J. T. 'Estimating agricultural supply response with the Nerlove Model: A survey', International Economic Review, Vol. 18, (1977) pp. 257-292.

Bhattacharyya, S. and Lafontaine, F. 'Double-sided moral hazard and the nature of share contracts', RAND Journal of Economics, Vol. 26, (1995) pp. 761-781.

Boswijk, H. P. 'Testing for an unstable root in conditional and structural error correction models', Journal of Econometrics, Vol. 63, (1994) pp. 37-60.

Chavas, J.-P. Risk Analysis in Theory and Practice (Amsterdam: Elsevier, 2004).

Cook, M. L. 'The future of US agricultural co-operatives: A neo-institutional approach', American Journal of Agricultural Economics, Vol. 77, (1995) pp. 1153-1159.

Dawson, P. J., Tiffin, A. L. and White, B. 'Optimal hedging ratios for wheat and barley at the LIFFE: A GARCH approach', Journal of Agricultural Economics, Vol. 51, (2000) pp. 147-161.

Diebold, F. X. Elements of Forecasting (Cincinatti, OH: South-Western College Publishing, 1998).

Ederington, L. H. 'The hedging performance of the new futures markets', Journal of Finance, Vol. 34, (1979) pp. 157-170.

Eisenhardt, K. M. 'Agency theory: An assessment and review', Academy of Management Review, Vol. 14, (1989) pp. 57-74.

Fulton, M. and Giannakas, K. 'Organizational commitment in a mixed oligopoly: Agricultural co-operatives and investor owned firms', American Journal of Agricultural Economics, Vol. 83, (2001) pp. 1258-1265.

Furubotn, E. G. and Richter, R. Institutions and Economic Theory: The Contribution of the New Institutional Economics, (Ann Arbor, MI: The University of Michigan Press, 1997).

Gibbons, R. 'Incentives between firms (and within)', Management Science, Vol. 51, (2005) pp. $2-17$.

Harwood, J., Heifner, R., Coble, K., Perry, J. and Somwaru, A. Managing Risk in Farming: Concepts, Research, and Analysis (Washington DC: Market and Trade Economics Division and Resource Economics Division, Economic Research Service, USDA; Agricultural Economic Report No. 774, 1999).

Holmstrom, B. and Milgrom, P. 'Aggregation and linearity in the provision of intertemporal incentives', Econometrica, Vol. 55, (1987) pp. 303-328.

Knoeber, C. R. 'Land and livestock contracting in agriculture: A principal-agent perspective', Chapter 5920, in B. Bouckaert and G. de Geest (eds), Encyclopedia of Law \& Economics (Cheltenham: Edward Elgar and the University of Ghent, 1999, pp. 1133-1153). 
Kuiper, W. E., Pennings, J. M. E. and Meulenberg, M. T. G. 'Identification by full adjustment: Evidence from the relationship between futures and spot prices', European Review of Agricultural Economics, Vol. 29, (2002) pp. 67-84.

Lien, D. and Tse, Y. K. 'Some recent developments in futures hedging', Chapter 5 in M. McAleer and L. Oxley (eds), Contributions to Financial Econometrics (Oxford: Blackwell Publishing, 2002, pp. 121-160).

Meyer, J. and von Cramon-Taubadel, S. 'Asymmetric price transmission: A survey', Journal of Agricultural Economics, Vol. 55, (2004) pp. 581-611.

Milgrom, P. and Roberts, J. Economics, Organization and Management (Englewood Cliffs, NJ: Prentice Hall, 1992).

Moschini, G. and Lapan, H. 'The hedging role of options and futures under joint price, basis, and production risk', International Economic Review, Vol. 36, (1995) pp. 1025-1049.

Nerlove, M. 'Adaptive expectations and cobweb phenomena', Quarterly Journal of Economics, Vol. 73, (1958a) pp. 227-240.

Nerlove, M. The Dynamics of Supply: Estimation of Farmers' Response to Price (Baltimore, MD: The Johns Hopkins Press, 1958b).

Pagan, A. R. 'Econometric issues in the analysis of regressions with generated regressors', International Economic Review, Vol. 25, (1984) pp. 221-247.

Pennings, J. M. E. and Wansink, B. 'Channel contract behaviour: The role of risk attitudes, risk perceptions, and channel members' market structures', Journal of Business, Vol. 77, (2004) pp. 697-723.

Pennings, J. M. E. and Garcia, P. 'Hedging behaviour in small and medium-sized enterprises: The role of unobserved heterogeneity', Journal of Banking \& Finance, Vol. 28, (2004) pp. 951-78.

Pennings, J. M. E. and Meulenberg, M. T. G. 'The hedging performance in new agricultural futures markets: A note', Agribusiness: An International Journal, Vol. 13, (1997) pp. 295300.

Sexton, R. J. and Lavoie, N. 'Food processing and distribution: An industrial organization approach', Chapter 15, in B. Gardner and G. Rausser (eds), Handbook of Agricultural Economics - Volume 1B, Marketing, Distribution and Consumers (Amsterdam: North-Holland, 2001).

Smidts, A. Decision Making under Risk (Wageningen: Pudoc, Wageningen Economic Studies No. 18, 1990).

Working, H. 'Futures trading and hedging', American Economic Review, Vol. 43, (1953) pp. 314-343.

Yoo, J. and Maddala, G. S. 'Risk premia and price volatility in futures markets', Journal of Futures Markets, Vol. 11, (1991) pp. 165-77.

Young, N. A. The Dutch Ware Potato Marketing System (Ashford: Centre for European Agricultural Studies, Report No. 9, 1977). 